\title{
New Fuzzy Normed Spaces
}

\author{
Jehad R. Kider*
}

Received 20, April , 2011

Accepted 4, December, 2011

\begin{abstract}
:
In this paper the research introduces a new definition of a fuzzy normed space then the related concepts such as fuzzy continuous, convergence of sequence of fuzzy points and Cauchy sequence of fuzzy points are discussed in details.
\end{abstract}

Key words: fuzzy set, fuzzy normed space, sequence of fuzzy points, fuzzy continuous.

S1:Basic Concepts About Fuzzy

Sets:

\section{Definition 1.1: [1]}

Let $\mathrm{X}$ be a nonempty set of elements. A fuzzy set $\tilde{A}$ in $X$ is characterized by a membership function, $\mu_{\tilde{A}}: X \rightarrow[0.1]$. Then $\tilde{A}$ can be written by $\tilde{\mathrm{A}}=\left\{\left(\mathrm{X}, \mu_{\tilde{\mathrm{A}}}\right.\right.$ (x) $\left.\mid \mathrm{x} \in \mathrm{X}, 0 \leq \mu_{\tilde{\mathrm{A}}}(\mathrm{x}) \leq 1\right\}$

\section{Definition 1.2: [1]}

Let $\tilde{A}$ and $\tilde{U}$ be two fuzzy sets in $\mathrm{X}$ then

1. $\tilde{\mathrm{A}} \subseteq \tilde{\mathrm{U}} \Leftrightarrow \mu_{\tilde{\mathrm{A}}}(\mathrm{x}) \leq \mu_{\tilde{\mathrm{U}}}(\mathrm{x})$ for all $\mathrm{x} \in \mathrm{X}$.

2. $\tilde{\mathrm{A}}=\tilde{\mathrm{U}} \Leftrightarrow \mu_{\tilde{\mathrm{A}}}(\mathrm{x})=\mu_{\mathrm{U}}(\mathrm{x})$ for all $\mathrm{x} \in \mathrm{X}$.

3. Then complement of $\tilde{A}$ (denoted by $\tilde{\mathrm{A}}^{\mathrm{c}}$ ) is also a fuzzy set with membership function $\mu_{\tilde{\AA}}^{c}(\mathrm{x})=1-\mu_{\tilde{\AA}}$ (X) for all $\mathrm{x} \in \mathrm{X}$.

4. $\tilde{\mathrm{A}}=\emptyset \Leftrightarrow \mu_{\tilde{\mathrm{A}}}(\mathrm{x})=0$ for all $\mathrm{x}$ $\in X$, where $\emptyset$ is the empty fuzzy set.

\section{Definition 1.3: [2],[3]}

A fuzzy point $P_{x}$ in $X$ is a fuzzy set with membership function

$\mu_{\mathrm{Px}}(\mathrm{y})= \begin{cases}\alpha & \text { if } y=x \\ 0 & \text { otherwise }\end{cases}$

For all $\mathrm{y} \in \mathrm{X}$ where $0<\alpha<1$. We denote this fuzzy point by $\mathrm{x}_{\alpha}$ or $(\mathrm{x}, \alpha)$.

Definition 1.4: [4],[5]

Two fuzzy points $\mathrm{x}_{\alpha}$ and $\mathrm{y}_{\beta}$ are said to be equal if $\mathrm{x}=\mathrm{y}$ and $\alpha=\beta$ where $\alpha, \beta \in$ $(0,1]$.

\section{Definition 1.5: [5],[6]}

Let $\mathrm{x}_{\alpha}$ be a fuzzy point and $\tilde{\mathrm{A}}$ a fuzzy set in $X$. then $x_{\alpha}$ is said to be in $\tilde{A}$ or belongs to $\tilde{\mathrm{A}}$ denoted by $\mathrm{x}_{\alpha} \in \tilde{\mathrm{A}}$ if $\alpha \leq$ $\mu_{\tilde{\mathrm{A}}}(\mathrm{x})$.

Definition 1.6: [6],[7]

Let $\mathrm{f}$ be a function from a nonempty set $\mathrm{X}$ into a nonempty set $\mathrm{Y}$. If $\tilde{U}$ is a fuzzy set in $\mathrm{Y}$ then $\mathrm{f}^{-1}$ ( $\tilde{\mathrm{U}}$ ) is a fuzzy set in $X$ with membership function $\mu_{f^{-1} \text { (Û) }}=\mu_{\tilde{U}}$ of.

If $\tilde{\mathrm{A}}$ is a fuzzy set in $\mathrm{X}$ then $\mathrm{f}(\tilde{\mathrm{A}})$ is a fuzzy set in $\mathrm{Y}$ with membership

$\mu_{\mathrm{f}(\tilde{\mathrm{A}})}(\mathrm{y})=\left\{\begin{array}{cc}\sup \left\{\mu_{\tilde{A}}(x) \mid x \in f^{-1}(y)\right\} \\ 0 & \text { otherwise }\end{array}\right.$ if $\mathrm{f}^{-1}(\mathrm{y}) \neq \varnothing$

For all $y \in Y$ where $\mathrm{f}^{-1}(\mathrm{y})=\{\mathrm{x} \in X$ $\mid \mathrm{f}(\mathrm{x})=\mathrm{y}\}$

Proposition 1.7: [7],[5]

Let $\mathrm{f}: \mathrm{X} \rightarrow \mathrm{Y}$ be a function then for a fuzzy point $\mathrm{x}_{\alpha}$ in $\mathrm{X}, \mathrm{f}\left(\mathrm{x}_{\alpha}\right)$ is a fuzzy point in $\mathrm{Y}$ and $\mathrm{f}\left(\mathrm{x}_{\alpha}\right)=\mathrm{f}(\mathrm{x})_{\alpha}$.

Definition 1.8: [8],[3]

Let $X$ be a vector space over field $\mathbf{K}$ and let $\tilde{\mathrm{A}}$ be a fuzzy set in X. then $\tilde{\mathrm{A}}$ is called a fuzzy subspace of $X$ if for all $\mathrm{x}, \mathrm{y} \in \mathrm{X}$ and $\lambda \in \mathbf{K}$.

(i) $\mu_{\tilde{A}}(x+y) \geq \min \left\{\mu_{\tilde{A}}(x), \mu_{\tilde{A}}(y)\right\}$

(ii) $\mu_{\tilde{\mathrm{A}}}(\lambda \mathrm{x}) \geq \mu_{\tilde{\mathrm{A}}}(\mathrm{x})$

S2: Fuzzy Normed Spaces

Definition 2.1: let $X$ be a vector space over field 
$\mathbf{K}(\mathbf{K}=\mathrm{R}$ or $\mathbf{K}=\mathrm{C})$.Put $\mathrm{I}=[0,1]$ then $\tilde{\mathrm{N}}: \mathrm{X} \times \mathrm{I} \rightarrow \mathrm{I}$ is said to be a fuzzy norm on $X$ if for each $x, y \in X$ and $\lambda \in K$ $\left(\mathrm{N}_{1}\right)$ if $\alpha=0$ then $\tilde{\mathrm{N}}(\mathrm{x}, \alpha)=0$.

$\left(\mathrm{N}_{2}\right)$ if $\alpha \neq 0$ then $\tilde{\mathrm{N}}(\mathrm{x}, \alpha)=0$ if and only if $x=0$.

$\left(\mathrm{N}_{3}\right) \tilde{\mathrm{N}}(\lambda \mathrm{x}, \alpha)=|\lambda| \tilde{\mathrm{N}}(\mathrm{x}, \alpha)$

$\left(\mathrm{N}_{4}\right) \tilde{\mathrm{N}}(\mathrm{x}+\mathrm{y}, \alpha) \leq \tilde{\mathrm{N}}(\mathrm{x}, \alpha)+\tilde{\mathrm{N}}(\mathrm{y}, \alpha)$

(N5) if $0<\sigma \leq \alpha<1$ then $\tilde{\mathrm{N}}(\mathrm{x}, \alpha) \leq$ $\tilde{\mathrm{N}}(\mathrm{x}, \sigma)$ and there exists $0<\alpha_{\mathrm{n}}<\alpha$ such that $\lim _{\mathrm{n} \rightarrow \infty} \tilde{\mathrm{N}}\left(\mathrm{x}, \alpha_{\mathrm{n}}\right)=\tilde{\mathrm{N}}(\mathrm{x}, \alpha)$.

Then $\tilde{N}$ is called fuzzy norm and $(X, \tilde{N})$ is called fuzzy normed space.

Now we introduce some propositions to explain the relation between ordinary normed space and fuzzy normed space.

\section{Proposition 2.2:}

Let $(\mathrm{X},\|\|$.$) be an ordinary normed$ space, define $\tilde{\mathrm{N}}(\mathrm{x}, \alpha)=\frac{1}{\alpha}\|\mathrm{x}\|$ for $\alpha>0$ and $\tilde{N}(x, \alpha)=0$ for $\alpha=0$. Then $(X, \tilde{N})$ is a fuzzy normed space

Proof: let $\mathrm{x}, \mathrm{y} \in \mathrm{X}$ and $\gamma \in \mathbf{K}$. Then

$\left(\mathrm{N}_{1}\right)$ if $\alpha=0$ then $\tilde{\mathrm{N}}(\mathrm{x}, \alpha)=0$.

$\left(\mathrm{N}_{2}\right)$ if $\alpha \neq 0$ then $\tilde{\mathrm{N}}(\mathrm{x}, \alpha)=0 \Leftrightarrow \frac{1}{\alpha}\|\mathrm{x}\|=0$ $\Leftrightarrow\|\mathrm{x}\|=0 \Leftrightarrow \mathrm{x}=0$.

$\left(\mathrm{N}_{3}\right) \tilde{\mathrm{N}}(\gamma \mathrm{x}, \alpha)=\frac{1}{\alpha}\|\gamma \mathrm{x}\|=\frac{|\gamma|}{\alpha}\|\mathrm{x}\|=|\gamma|$

$\tilde{\mathrm{N}}(\mathrm{x}, \alpha)$.

$\left(\mathrm{N}_{4}\right) \tilde{\mathrm{N}}(\mathrm{x}+\mathrm{y}, \alpha)=\frac{1}{\alpha}\|\mathrm{x}+\mathrm{y}\| \leq$ $\frac{1}{\alpha}\|\mathrm{x}\|+\frac{1}{\alpha}\|\mathrm{y}\|=\tilde{\mathrm{N}}(\mathrm{x}, \alpha)+\tilde{\mathrm{N}}(\mathrm{y}, \alpha)$.

$\left(\mathrm{N}_{5}\right)$ if $0<\sigma \leq \alpha<1$ then $\frac{\|x\|}{\alpha} \leq \frac{\|x\|}{\sigma}$ that is $\tilde{\mathrm{N}}(\mathrm{x}, \alpha) \leq \tilde{\mathrm{N}}(\mathrm{x}, \sigma)$ then there exists $0<\alpha_{n}<\alpha$ [ This is possible by taking $\left.\alpha_{n}=\left(1-\frac{1}{n}\right) \alpha\right]$ such that lim $n \rightarrow \infty \tilde{N}\left(x, \alpha_{n}\right)=\tilde{N}(x, \alpha)$.

The proof of the following result is clear. Hence is omitted

\section{Proposition 2.3:}

Let $(X, \tilde{N})$ be a fuzzy normed space if for each $\mathrm{x} \in \mathrm{X}$ define

$\|\mathrm{x}\|=\tilde{\mathrm{N}}(\mathrm{x}, \alpha)$,for some $\alpha \in(0,1]$ .Then $(X,\|\|$.$) is an ordinary normed$ space.

\section{Example 2.4:}

Let $\mathrm{X}=\mathbf{R}$, then $\tilde{N}(\mathrm{x}, \alpha)=\frac{1}{\alpha}|\mathrm{x}|$ is a

fuzzy norm on $\mathbf{R}$ by proposition 2.2 called the usual fuzzy norm.

\section{Remark 2.5:}

From the definition 2.1 we obtain by induction the generalized of $\left(\mathrm{N}_{4}\right)$

$\tilde{\mathrm{N}}\left(\mathrm{x}_{1}-\mathrm{x}_{\mathrm{n}}, \alpha\right) \leq \tilde{\mathrm{N}}\left(\mathrm{x}_{1}-\mathrm{x}_{2}, \alpha\right)+\tilde{\mathrm{N}}\left(\mathrm{x}_{2}-\right.$ $\left.\mathrm{x}_{3}, \alpha\right)+\ldots+\tilde{\mathrm{N}}\left(\mathrm{x}_{\mathrm{n}-1}-\mathrm{x}_{\mathrm{n}}, \alpha\right)$

Where $\left(\mathrm{x}_{2}, \alpha\right),\left(\mathrm{x}_{3}, \alpha\right), \ldots,\left(\mathrm{x}_{\mathrm{n}-1}, \alpha\right) \in \mathrm{X}$

\section{Definition 2.6:}

A fuzzy subspace $\hat{Y}$ of a fuzzy normed space $(X, \tilde{N})$ is a fuzzy subspace of $X$ considered as a vector space with the fuzzy norm obtained by restricting the fuzzy norm on $\mathrm{X}$ to $\hat{\mathrm{Y}}$.

S3: Open Fuzzy Sets, Closed Fuzzy Sets, Fuzzy Continuity of Functions In this section we introduce some new concepts

\section{Definition 3.1:}

Let $(X, \tilde{N})$ be a fuzzy normed space. Given $\mathrm{x}_{\alpha} \in \mathrm{X}$, where $\alpha \in(0,1]$ and a real number $r>0$

(i) $\widetilde{\mathrm{o}}\left(\mathrm{x}_{\alpha}, \mathrm{r}\right)=\left\{\mathrm{y}_{\beta} \in \mathrm{X}: \tilde{\mathrm{N}}(\mathrm{x}-\mathrm{y}, \lambda)<\mathrm{r}\right\}$ is open fuzzy ball, where $\lambda=\min \{\alpha, \beta\}$. (ii) $\widetilde{\mathrm{B}}\left(\mathrm{x}_{\alpha}, \mathrm{r}\right)=\left\{\mathrm{y}_{\beta} \in \mathrm{X}: \tilde{\mathrm{N}}(\mathrm{x}-\mathrm{y}, \lambda) \leq \mathrm{r}\right\}$ is closed fuzzy ball, where $\lambda=\min \{\alpha$, $\beta\}$.

(iii) $\quad \mathrm{S}\left(\mathrm{x}_{\alpha}, \mathrm{r}\right)=\left\{\mathrm{y}_{\beta} \in \mathrm{X}: \tilde{\mathrm{N}}(\mathrm{x}-\mathrm{y}, \lambda)=\right.$ $r\}$ is fuzzy sphere, where $\lambda=\min \{\alpha, \beta\}$.

In all three cases, $x_{\alpha}$ is called the center and $\mathrm{r}$ is radius.

\section{Definition 3.2:}

A fuzzy set $\tilde{A}$ in fuzzy normed space $(X, \tilde{N})$ is said to be open if it contains a fuzzy ball about each of its, fuzzy element.

A fuzzy set $\widetilde{\mathbf{D}}$ is said to be closed fuzzy set if it's complement is open fuzzy set.

\section{Definition 3.3:}

Let $(\mathrm{X}, \tilde{\mathbf{N}})$ be a fuzzy normed space, an open fuzzy ball $\tilde{\mathrm{O}}\left(\mathrm{x}_{\alpha}, \varepsilon\right)$ of radius $\varepsilon$ is 
often called an $\varepsilon$-neighborhood of $\mathrm{x}_{\alpha}$ (here $\varepsilon>0$ ).

By a neighborhood of $\mathrm{x}_{\alpha}$ we mean a fuzzy set of $X$ which contains an $\varepsilon$ neighborhood of $\mathrm{x}_{\alpha}$.

\section{Definition 3.4:}

The fuzzy point $\mathrm{x}_{\alpha}$ is called an interior point of the fuzzy set $\tilde{A}$ if $\tilde{A}$ is a neighborhood of $\mathrm{x}_{\alpha}$. The interior of $\tilde{\mathrm{A}}$ is the set of all interior fuzzy points of $\tilde{\mathrm{A}}$ and is denoted by $\operatorname{int}(\tilde{\mathrm{A}})$.

$\operatorname{Int}(\tilde{\mathrm{A}})$ is open fuzzy set and is the largest open fuzzy set contained in $\tilde{A}$.

\section{Definition 3.5:}

Let $\left(\mathrm{X}, \tilde{\mathbf{N}}_{1}\right)$ and $\left(\mathrm{Y}, \tilde{\mathrm{N}}_{2}\right)$ be a fuzzy normed spaces. A mapping $\mathrm{T}: \mathrm{X} \rightarrow \mathrm{Y}$ is said to be fuzzy continuous at the fuzzy point $\mathrm{x}_{\alpha} \in \mathrm{X}$ where $\alpha \in(0,1]$ if for every $\varepsilon>0$ there is $\delta>0$ such that $\tilde{\mathrm{N}}_{2}(\mathrm{~T}(\mathrm{y})-\mathrm{T}(\mathrm{x}), \lambda)<\varepsilon$, for all $\mathrm{y}_{\beta} \in \mathrm{X}$ satisfying $\quad \tilde{\mathrm{N}}_{1}(\mathrm{y}-\mathrm{x}, \lambda)<\delta$, where $\lambda$ $=\min \{\alpha, \beta\} . \quad \mathrm{T}$ is said to be fuzzy continuous if it is fuzzy continuous at every fuzzy point $\mathrm{x}_{\alpha} \in \mathrm{X}$.

\section{Theorem 3.6:}

A mapping $\mathrm{T}$ of a fuzzy normed space $\left(\mathrm{X}, \tilde{\mathrm{N}}_{1}\right)$ into a fuzzy normed space $\left(\mathrm{Y}, \tilde{\mathrm{N}}_{2}\right)$ is fuzzy continuous if and only if the inverse image of any open fuzzy set in $\mathrm{Y}$ is open fuzzy set in $\mathrm{X}$.

\section{Proof:}

Suppose T is fuzzy continuous. Let O be open fuzzy set in $Y$ and $\tilde{U}$ is the inverse image of $\tilde{\mathrm{O}}$ i.e $\mathrm{T}^{-1}(\tilde{\mathrm{O}})=\tilde{\mathrm{U}}$. If $\tilde{U}=\varnothing$ it is open fuzzy set. Let $\tilde{U} \neq \varnothing$, for any $\mathrm{x}_{\alpha} \in \tilde{\mathrm{U}}$ where $\alpha \in(0,1]$. Let $\mathrm{y}_{\alpha}$ $=\mathrm{T}\left(\mathrm{x}_{\alpha}\right)=\mathrm{T}(\mathrm{x})_{\alpha} \quad[$ By proposition 1.7] since $\tilde{O}$ is open, it contains as $\varepsilon^{-}$ neighborhood $\mathrm{N}_{2}$ of $\mathrm{y}_{\alpha}$. Since $\mathrm{T}$ is fuzzy continuous, $\mathrm{x}_{\alpha}$ has an $\delta$ neighborhood $\mathrm{N}_{1}$ which is mapped into $\mathrm{N}_{2}$. Since $\mathrm{N}_{2} \subset \tilde{\mathrm{O}}$ we have $\mathrm{N}_{1} \subset \tilde{\mathrm{U}}$ so that $\tilde{U}$ is open fuzzy set because $\mathrm{x}_{\alpha} \in \tilde{\mathrm{U}}$ was arbitrary.

Conversely, assume that the inverse image of every open fuzzy set in $\mathrm{Y}$ is open fuzzy set in $X$. Then for each $\mathrm{x}_{\alpha} \in X$ where $\alpha \in(0,1]$ and any $\varepsilon$ - neighborhood $\mathrm{N}_{2}$ of $\mathrm{T}(\mathrm{x})_{\alpha}$ the inverse image of $N_{1}$ is open since $N_{2}$ is open and $\mathrm{N}_{1}$ contains $\mathrm{x}_{\alpha}$. Hence $\mathrm{N}_{1}$ is also contain a $\delta$-neighborhood of $\mathrm{x}_{\alpha}$ which is mapped into $\mathrm{N}_{2}$ because $\mathrm{N}_{1}$ is mapped into $\mathrm{N}_{2}$. Consequently $\mathrm{T}$ is fuzzy continuous at $\mathrm{x}_{\alpha}$. Since $\mathrm{x}_{\alpha} \in \mathrm{X}$ was arbitrary $\mathrm{T}$ is fuzzy continuous.

\section{Definition 3.7:}

Let $\tilde{A}$ be a fuzzy set in a fuzzy normed space $(\mathrm{X}, \tilde{\mathrm{N}})$. Then a fuzzy point $\mathrm{x}_{\alpha} \in$ $X$ where $\alpha \in(0,1]$ (which may or not be a fuzzy element of $\tilde{A}$ ) is called a limit of $\tilde{A}$ if every neighborhood of $x_{\alpha}$ contains at least one fuzzy element $\mathrm{y}_{\beta}$ $\in \tilde{A}$ distinct from $x_{\alpha}$. The fuzzy set consisting of $\tilde{\mathrm{A}}$ and its limit fuzzy points is called closure of $\tilde{\mathrm{A}}$ and is denoted by $\operatorname{cl}(\tilde{\mathrm{A}})$. It is the smallest closed fuzzy set containing $\tilde{A}$.

\section{Definition 3.8:}

A fuzzy set $\tilde{A}$ of a fuzzy normed space $(\mathrm{X}, \tilde{\mathrm{N}})$ is said to be dense in $\mathrm{X}$ if $\operatorname{cl}(\tilde{\mathrm{A}})=\mathrm{X}$.

\section{S4: Convergence, Cauchy Fuzzy Sequences}

In this section we will introduce some new concepts and results

\section{Definition4.1:}

A sequence of fuzzy points $\left\{\left(x_{n}, \alpha_{n}\right)\right\}$ in a fuzzy normed space $(X, \tilde{\mathrm{N}})$ is said to be convergent to $\mathrm{x}_{\alpha}$ in $\mathrm{X}$ where $\alpha, \alpha_{\mathrm{n}}$ $\in(0,1]$ for $\mathrm{i}=1,2, \ldots$ if $\quad \lim _{\mathrm{n} \rightarrow \infty} \tilde{\mathrm{N}}\left(\mathrm{x}_{\mathrm{n}}\right.$ $-x, \lambda)=0, x_{\alpha}$ is called the limit if $\left\{\left(\mathrm{x}_{\mathrm{n}}, \alpha_{\mathrm{n}}\right)\right\}$ and we write $\lim _{\mathrm{n} \rightarrow \infty}\left(\mathrm{x}_{\mathrm{n}}, \alpha_{\mathrm{n}}\right)=$ $\mathrm{x}_{\alpha}$ or simply $\left(\mathrm{x}_{\mathrm{n}}, \alpha_{\mathrm{n}}\right) \rightarrow \mathrm{x}_{\alpha}$,if $\left\{\left(\mathrm{x}_{\mathrm{n}}, \alpha_{\mathrm{n}}\right)\right\}$ is not convergent then it is called divergent.

\section{Remark 4.2:}

If $\left(\mathrm{x}_{\mathrm{n}}, \alpha_{\mathrm{n}}\right) \rightarrow \mathrm{x}_{\alpha}$, an $\varepsilon>0$ being given, there is a positive integer $\mathrm{N}$ such that $\left(\mathrm{x}_{\mathrm{n}}, \alpha_{\mathrm{n}}\right)$ with $\mathrm{n}>\mathrm{N}$ lie in $\varepsilon$ neighborhood $\tilde{\mathrm{O}}\left(\mathrm{x}_{\alpha}, \varepsilon\right)$ of $\mathrm{x}_{\alpha}$ that is: $\tilde{N}\left(x_{n}-x, \lambda\right)<\varepsilon$, for all $n>N$.

\section{Definition4.3:}

We call a nonempty fuzzy set $\tilde{A}$ in $(\mathrm{X}, \tilde{\mathrm{N}})$ bounded if its fuzzy diameter 
$\delta(\tilde{\mathrm{A}})=\sup \left\{\tilde{\mathbf{N}}(\mathrm{x}-\mathrm{y}, \lambda): \mathrm{x}_{\alpha,} \mathrm{y}_{\beta} \in \tilde{\mathrm{A}}, \lambda\right.$

$=\min \{\alpha, \beta\}\}$ is finite.

\section{Definition4.4:}

In a fuzzy normed space $(X, \tilde{N})$ we call a sequence $\left\{\left(x_{n}, \alpha_{n}\right)\right\}$ is bounded if the corresponding fuzzy set is bounded.

\section{Remark 4.5:}

If $\tilde{A}$ is a bounded fuzzy set then $\tilde{A} \subset \tilde{O}$ $\left(\mathrm{x}_{\alpha}, \mathrm{r}\right)$ where $\mathrm{x}_{\alpha} \in \tilde{\mathrm{A}}$ is any fuzzy element and $r>0$ is a (sufficiently large) real number.

\section{Theorem 4.6:}

Let $(\mathrm{X}, \tilde{\mathrm{N}})$ be a fuzzy normed space. Then (i) a convergent fuzzy sequence in $\mathrm{X}$ is bounded and its limit is unique.

(ii) if $\left(\mathrm{x}_{\mathrm{n}}, \alpha_{\mathrm{n}}\right) \rightarrow \mathrm{x}_{\alpha}$ and $\left(\mathrm{y}_{\mathrm{m}}, \beta_{\mathrm{m}}\right) \rightarrow \mathrm{y}_{\beta}$ in $X$, where $\alpha, \alpha_{i}, \beta, \beta_{i} \in(0.1] \mathrm{i}=1,2$,

Then $\tilde{\mathrm{N}}\left(\mathrm{x}_{\mathrm{n}}-\mathrm{y}_{\mathrm{m}}, \lambda\right) \rightarrow \tilde{\mathrm{N}}(\mathrm{x}-\mathrm{y}, \lambda)$ ,where $\lambda=\min \left\{\alpha, \alpha_{\mathrm{i}}, \beta \beta_{\mathrm{i}}\right\}$.

\section{Proof:}

(i)Suppose that $\left(\mathrm{x}_{\mathrm{n}}, \alpha_{\mathrm{n}}\right) \rightarrow \mathrm{x}_{\alpha}$ then taking $\varepsilon=1$ we can find $\mathrm{N}>0$ such that $\tilde{\mathrm{N}}\left(\mathrm{x}_{\mathrm{n}}-\mathrm{x}_{\alpha}\right)<1$ for all $\mathrm{n}>\mathrm{N}$. Hence by remark 2.5 for all $\mathrm{n}$ we have $\tilde{\mathrm{N}}\left(\mathrm{x}_{\mathrm{n}}-\mathrm{x}_{\alpha}, \lambda\right)<1+\mathrm{a}$, where $\mathrm{a}=$ $\max \left\{\tilde{\mathrm{N}}\left(\mathrm{x}_{1}-\mathrm{x}_{2}, \lambda\right) \quad, \tilde{\mathrm{N}}\left(\mathrm{x}_{2}-\mathrm{x}_{3}\right.\right.$ $\left., \lambda), \ldots, \tilde{\mathrm{N}}\left(\mathrm{x}_{\mathrm{n}}-\mathrm{x}_{\alpha}, \lambda\right)\right\}$, where $\lambda=$ $\min \left\{\alpha_{1}, \alpha_{2}, \ldots, \alpha_{n}, \ldots\right\}$ [Here $\lambda$ exists since this set is bounded].This shows that $\left\{\left(\mathrm{x}_{\mathrm{n}}, \alpha_{\mathrm{n}}\right)\right\}$ is bounded. Now, assuming that $\left(\mathrm{x}_{\mathrm{n}}, \alpha_{\mathrm{n}}\right) \rightarrow \mathrm{x}_{\alpha}$ and

$\left(\mathrm{x}_{\mathrm{n}}, \alpha_{\mathrm{n}}\right) \rightarrow \mathrm{z}_{\beta}$, we obtain from $\left(\mathrm{N}_{4}\right) 0 \leq$ $\tilde{\mathrm{N}}\left(\mathrm{x}_{\alpha}-\mathrm{z}_{\beta}, \lambda\right) \leq \tilde{\mathrm{N}}\left(\mathrm{x}_{\alpha}-\mathrm{x}_{\mathrm{n}}, \lambda\right)+\tilde{\mathrm{N}}\left(\mathrm{x}_{\mathrm{n}}\right.$ $\left.-z_{\beta}, \lambda\right) \rightarrow 0+0$.where $\lambda=$ $\min \left\{\beta, \alpha_{1}, \alpha_{2}, \ldots, \alpha_{n}, \ldots\right\}[$ Here $\lambda$ exists since this set is bounded ] .

Thus $\tilde{\mathrm{N}}\left(\mathrm{x}_{\alpha}-\mathrm{z}_{\beta}, \lambda\right)=0$ which implies that $\mathrm{x}_{\alpha}=\mathrm{z}_{\beta}$.

(ii)By remark 2.5 we have $\tilde{\mathrm{N}}\left(\mathrm{x}_{\mathrm{n}}-\mathrm{y}_{\mathrm{m}}\right.$,

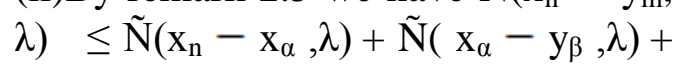
$\tilde{\mathrm{N}}\left(\mathrm{y}_{\beta}-\mathrm{y}_{\mathrm{m}}, \lambda\right)$.

Hence we obtain

$\tilde{\mathrm{N}}\left(\mathrm{x}_{\mathrm{n}}-\mathrm{y}_{\mathrm{m}}, \lambda\right)-\tilde{\mathrm{N}}\left(\mathrm{x}_{\alpha}-\mathrm{y}_{\beta}, \lambda\right) \leq \tilde{\mathrm{N}}\left(\mathrm{x}_{\mathrm{n}}-\right.$ $\left.\mathrm{x}_{\alpha}, \lambda\right)+\tilde{\mathrm{N}}\left(\mathrm{y}_{\mathrm{m}}-\mathrm{y}_{\beta}, \lambda\right)$.
And a similar inequality by interchanging $\left(\mathrm{x}_{\mathrm{n}}, \alpha_{\mathrm{n}}\right)$ and $\mathrm{x}_{\alpha}$ as well as $\left(\mathrm{y}_{\mathrm{m}}, \beta_{\mathrm{m}}\right)$ and $\mathrm{y}_{\beta}$ and multiplying by -1 . Together $\mid \tilde{\mathrm{N}}\left(\mathrm{x}_{\mathrm{n}}-\mathrm{y}_{\mathrm{m}}, \lambda\right)-\tilde{\mathrm{N}}\left(\mathrm{x}_{\alpha}-\mathrm{y}_{\beta}\right.$ $, \lambda) \mid \leq \tilde{\mathrm{N}}\left(\mathrm{x}_{\mathrm{n}}-\mathrm{x}_{\alpha}, \lambda\right)+\tilde{\mathrm{N}}\left(\mathrm{y}_{\mathrm{m}}-\mathrm{y}_{\beta}, \lambda\right)$ $\rightarrow 0$ as $\mathrm{n} \rightarrow \infty$. Where $\lambda=\min \{\alpha, \beta$, $\left.\alpha_{\mathrm{n}}, \beta_{\mathrm{m}}\right\}$.

\section{Definition 4.7:}

A sequence $\left\{\left(\mathrm{x}_{\mathrm{n}}, \mathrm{a}_{\mathrm{n}}\right)\right\}$ in a fuzzy normed space $(X, \tilde{N})$ is said to be Cauchy if for

every $\varepsilon>0$ there is integer $\mathrm{N}>0$ such that $\tilde{\mathrm{N}}\left(\mathrm{x}_{\mathrm{m}}-\mathrm{x}_{\mathrm{n}}, \lambda\right)<\varepsilon$ for every $\mathrm{m}, \mathrm{n}>$ $\mathrm{N}$,

where $\lambda=\min \left\{\alpha_{1}, \alpha_{2}, \ldots, \alpha_{\mathrm{n}}, \ldots\right\}$ [Here $\lambda$ exists since this set is bounded ] .

\section{Theorem 4.8:}

Every convergent fuzzy sequence in a fuzzy normed space $(\mathrm{X}, \tilde{\mathrm{N}})$ is Cauchy.

\section{Proof:}

Let $\left\{\left(x_{n}, \alpha_{n}\right)\right\}$ be a sequence of fuzzy points in $\mathrm{X}$ such that $\left(\mathrm{x}_{\mathrm{n}}, \alpha_{\mathrm{n}}\right) \rightarrow \mathrm{x}_{\alpha}$ then for every $\varepsilon>0$ there is an integer $\mathrm{N}>0$ such that $\tilde{\mathrm{N}}\left(\mathrm{x}_{\mathrm{n}}-\mathrm{x}_{\alpha}, \lambda\right)<\frac{\bar{s}}{2}$ for all $\mathrm{n}>$ $\mathrm{N}$.

Hence by $\left(\mathrm{N}_{4}\right)$ we obtain for $\mathrm{m}, \mathrm{n}>\mathrm{N}$.

$\tilde{\mathrm{N}}\left(\mathrm{x}_{\mathrm{m}}-\mathrm{x}_{\mathrm{n}}, \lambda\right) \leq \tilde{\mathrm{N}}\left(\mathrm{x}_{\mathrm{m}}-\mathrm{x}_{\alpha}, \lambda\right)+\tilde{\mathrm{N}}\left(\mathrm{x}_{\alpha}\right.$ $\left.-\mathrm{x}_{\mathrm{n}}, \lambda\right) \leq \frac{\varepsilon}{2}+\frac{\varepsilon}{2}=\varepsilon$.

This shows that $\left\{\left(\mathrm{x}_{\mathrm{n}}, \alpha_{\mathrm{n}}\right)\right\}$ is Cauchy. Where $\lambda=\min \left\{\alpha, \alpha_{1}, \alpha_{2}, \ldots, \alpha_{n}, \ldots\right.$ \}$[$ Here $\lambda$ exists since this set is bounded ] .

\section{Theorem 4.9:}

Let $\tilde{\mathrm{A}}$ be a nonempty fuzzy set in a fuzzy normed space $(\mathrm{X}, \tilde{\mathrm{N}})$ and $\operatorname{cl}(\tilde{\mathrm{A}})$ its closure.

Then

(i) $\quad \mathrm{x}_{\alpha} \in \operatorname{cl}(\tilde{\mathrm{A}})$ if and only if there is a fuzzy sequence $\left\{\left(x_{n}, \alpha_{n}\right)\right\}$ in $\tilde{A}$ such that $\left(\mathrm{x}_{\mathrm{n}}, \alpha_{\mathrm{n}}\right) \rightarrow \mathrm{x}_{\alpha}$ where $\alpha \in(0,1]$.

(ii) $\tilde{\mathrm{A}}$ is closed if and only if the situation $\left(\mathrm{x}_{\mathrm{n}}, \alpha_{\mathrm{n}}\right) \in \tilde{\mathrm{A}}$ and $\left(\mathrm{x}_{\mathrm{n}}, \alpha_{\mathrm{n}}\right) \rightarrow \mathrm{x}_{\alpha}$ implies $\mathrm{x}_{\alpha} \in \tilde{\mathrm{A}}$.

\section{Proof:}

(i)Let $\mathrm{x}_{\alpha} \in \mathrm{cl}(\tilde{\mathrm{A}})$. If $\mathrm{x}_{\alpha} \in \tilde{\mathrm{A}}$ a fuzzy sequence of that type is $\mathrm{x}_{\alpha}, \mathrm{x}_{\alpha}, \ldots$ 
If $\mathrm{x}_{\alpha} \notin \tilde{\mathrm{A}}$ then it must be a limit of $\tilde{\mathrm{A}}$. Hence for each $n=1,2, \ldots$ the fuzzy ball $\tilde{\mathrm{O}}\left(\mathrm{x}_{\alpha}, \frac{1}{n}\right)$ contains an $\left(\mathrm{x}_{\mathrm{n}}, \alpha_{\mathrm{n}}\right) \in \tilde{\mathrm{A}}$ and $\left(\mathrm{x}_{\mathrm{n}}, \alpha_{\mathrm{n}}\right) \rightarrow \mathrm{x}_{\alpha}$ because $\frac{1}{n} \rightarrow 0$ as $\mathrm{n} \rightarrow \infty$. Conversely, if $\left\{\left(\mathrm{x}_{\mathrm{n}}, \alpha_{\mathrm{n}}\right)\right\}$ is in $\tilde{\mathrm{A}}$ and $\left(\mathrm{x}_{\mathrm{n}}, \alpha_{\mathrm{n}}\right) \rightarrow \mathrm{x}_{\alpha}$ then $\mathrm{x}_{\alpha} \in \tilde{\mathrm{A}}$ or every neighborhood of $\mathrm{x}_{\alpha}$ contains a fuzzy point $\left(\mathrm{x}_{\mathrm{n}}, \alpha_{\mathrm{n}}\right) \neq \mathrm{x}_{\alpha}$ so that is $\mathrm{x}_{\alpha}$ a limit of $\tilde{\mathrm{A}}$. Hence $\mathrm{x}_{\alpha} \in \operatorname{cl}(\tilde{\mathrm{A}})$. It is clear that $\tilde{\mathrm{A}}=\operatorname{cl}(\tilde{\mathrm{A}})$.

(ii) $\tilde{\mathrm{A}}$ is closed if and only if $\tilde{\mathrm{A}}=\operatorname{cl}(\tilde{\mathrm{A}})$ so that (ii) follows readily from (i).

\section{Theorem 4.10:}

A mapping $\mathrm{T}: \mathrm{X} \rightarrow \mathrm{Y}$ of a fuzzy normed space $\left(X, \tilde{N}_{1}\right)$ into a fuzzy normed space $\left(\mathrm{Y}, \tilde{\mathrm{N}}_{2}\right)$ is fuzzy continuous at a fuzzy point $\mathrm{x}_{\alpha}, \in \mathrm{X}$ if and only if $\left(\mathrm{x}_{\mathrm{n}}, \alpha_{\mathrm{n}}\right) \rightarrow \mathrm{x}_{\alpha}$ implies $\left(\mathrm{T}\left(\mathrm{x}_{\mathrm{n}}\right), \alpha_{\mathrm{n}}\right) \rightarrow \mathrm{T}(\mathrm{x})_{\alpha}$.

\section{Proof:}

Assume that $\mathrm{T}$ is fuzzy continuous at $\mathrm{x}_{\alpha}$. Then given $\varepsilon>0$ there is $\delta>0$ such that $\tilde{\mathrm{N}}_{1}(\mathrm{y}-\mathrm{x}, \lambda)<\delta$ implies $\tilde{\mathrm{N}}_{2}(\mathrm{~T}(\mathrm{y})-$ $\mathrm{T}(\mathrm{x}), \lambda)<\varepsilon$. Let $\left(\mathrm{x}_{\mathrm{n}}, \alpha_{\mathrm{n}}\right) \rightarrow \mathrm{x}_{\alpha}$. Then there is $\mathrm{N}>0$ such that $\tilde{\mathrm{N}}\left(\mathrm{x}_{\mathrm{n}}-\mathrm{x}_{\alpha}, \lambda\right)<$ $\varepsilon$ for all $\mathrm{n}>\mathrm{N}$.Where $\lambda=$ $\min \{\alpha, \beta\}$.Hence for all $\mathrm{n}>\mathrm{N}$, $\tilde{\mathrm{N}}_{2}\left(\mathrm{~T}\left(\mathrm{x}_{\mathrm{n}}\right)-\mathrm{T}(\mathrm{x}), \lambda\right)<\varepsilon$ this means that $\left(\mathrm{T}\left(\mathrm{x}_{\mathrm{n}}\right), \alpha_{\mathrm{n}}\right) \rightarrow \mathrm{T}(\mathrm{x})_{\alpha}$.

Conversely, we assume that $\left(\mathrm{x}_{\mathrm{n}}, \alpha_{\mathrm{n}}\right) \rightarrow$ $\mathrm{x}_{\alpha}$ implies $\left(\mathrm{T}\left(\mathrm{x}_{\mathrm{n}}\right), \alpha_{\mathrm{n}}\right) \rightarrow \mathrm{T}(\mathrm{x})_{\alpha}$, and prove that $\mathrm{T}$ is fuzzy continuous at $\mathrm{x}_{\alpha}$. Suppose this is false. Then there is an $\varepsilon$ $>0$ such that for every $\delta>0$ there is $\mathrm{y}_{\beta}$ $\neq \mathrm{x}_{\alpha}$ satisfying $\tilde{\mathrm{N}}_{1}(\mathrm{y}-\mathrm{x}, \lambda)<\delta$ but $\tilde{\mathrm{N}}_{2}(\mathrm{~T}(\mathrm{y})-\mathrm{T}(\mathrm{x}), \lambda) \geq \varepsilon$.
In particular for $\delta=\frac{1}{n}$ there is $\left\{\left(\mathrm{x}_{\mathrm{n}}\right.\right.$, $\left.\alpha_{\mathrm{n}}\right)$ \} satisfying $\tilde{\mathrm{N}}_{1}\left(\mathrm{x}_{\mathrm{n}}-\mathrm{x}_{\alpha}, \lambda\right)<\frac{1}{n}$ but $\tilde{\mathrm{N}}_{2}\left(\mathrm{~T}\left(\mathrm{x}_{\mathrm{n}}\right)-\mathrm{T}(\mathrm{x}), \lambda\right) \geq \varepsilon$. Clearly $\left(\mathrm{x}_{\mathrm{n}}, \alpha_{\mathrm{n}}\right)$ $\rightarrow \mathrm{x}_{\alpha}$ but $\left.\left\{\mathrm{T}\left(\mathrm{x}_{\mathrm{n}}\right), \alpha_{\mathrm{n}}\right)\right\}$ does not converse to $\mathrm{T}(\mathrm{x})_{\alpha}$. This contradicts $\left(\mathrm{T}\left(\mathrm{x}_{\mathrm{n}}\right), \alpha_{\mathrm{n}}\right) \rightarrow \mathrm{T}(\mathrm{x})_{\alpha}$ and proves the theorem.

\section{References:}

1. Zadeh, A. L.1965. Fuzzy set, Information and Control. 8 : $338-$ 353.

2. Gregori, V. and Sapena, A.2002.On Fixed Point Theorems in Fuzzy Metric Spaces , Fuzzy Set and System .125:245-252.

3. Kider, J. R.2004.Fuzzy Locally Convex *- Algebra, Ph. D. Thesis, Technology University, Baghdad .

4.Bag, T. and Samanta, T. K.2003.Finite Dimensional Fuzzy Normed Linear Spaces, J. Fuzzy Math.11(3):687-705 .

5. Abdual Gawad, A.Q.2003. On Fuzzy Topological Dimension, Ph. D. Thesis, Baghdad University, Baghdad .

6.Bag, T. and Samanta, T. K.2008. A comparative Study of Fuzzy Norms on Linear Spaces , Fuzzy Sets and System. $159: 670-684$.

7. Lubna, K. A.2005. On Fuzzy Open Mapping, Ph. D. Thesis, College of Education, Al- Mustaniriyah University, Baghdad .

8.Mihet, D. 2007 . On Fuzzy Contractive Mapping in Fuzzy Mrtric, Fuzzy Sets and System. 158 : 915-921 . 


\section{فضاءات قيا سية ضبا بية جديدة}

جها د رمضا ن خضر

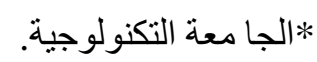

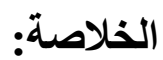

في هذا البحث قدمنا تعريف جديد للفضاء القياسي الضبابي ثم بعد ذللك قمنا بدر اسة المفاهيم المتعلقة بهذا التعريف مثلا الاستمر ارية الضبابيه و التقارب للمتتابعات التي عناصر ها نقاط ضبابيه ومنتابعات كوشي بتفاصيل اكثر. 